\section{Ocean Modelling}

Ocean Modelling 12 (2006) 290-301

\title{
On the solution of the carbonate chemistry system in ocean biogeochemistry models
}

\author{
Michael J. Follows ${ }^{\mathrm{a}, *}$, Taka Ito ${ }^{\mathrm{b}}$, Stephanie Dutkiewicz ${ }^{\mathrm{a}}$ \\ ${ }^{a}$ Department of Earth, Atmospheric and Planetary Sciences, Massachusetts Institute of Technology, \\ Cambridge, MA 02139, USA \\ ${ }^{\mathrm{b}}$ Joint Institute for the Study of Atmosphere and Ocean, P.O. Box 354235, University of Washington, \\ Seattle, WA 98195-4235, USA
}

Received 29 September 2004; received in revised form 27 May 2005; accepted 27 May 2005

Available online 28 June 2005

\begin{abstract}
We present a simplified method for solving the local equilibrium carbonate chemistry in numerical ocean biogeochemistry models. Compared to the methods typically used, the scheme is fast, efficient and compact. The accuracy of the solution is dictated by the number of species retained in the expression for alkalinity and there is almost no computational penalty for retaining minor contributions. We demonstrate that this scheme accurately reproduces the results of the commonly used method in the context of a three-dimensional global ocean carbon cycle model. Using this model we also show that neglecting the regional variations in surface dissolved inorganic phosphorus and silicic acid concentrations can lead to significant systematic bias in regional estimates of air-sea carbon fluxes using such models.
\end{abstract}

(c) 2005 Elsevier Ltd. All rights reserved.

\section{Introduction}

Numerical methods used to solve the equilibrium partitioning of the aquatic carbonate system typically involve the solution of a fifth, or higher, order polynomial using techniques such as

\footnotetext{
${ }^{*}$ Corresponding author.

E-mail addresses: mick@ocean.mit.edu (M.J. Follows), ito@atmos.washington.edu (T. Ito), stephd@ocean.mit.edu (S. Dutkiewicz).
}

$1463-5003 / \$$ - see front matter $\odot 2005$ Elsevier Ltd. All rights reserved. doi:10.1016/j.ocemod.2005.05.004 
Newton-Raphson iteration (e.g. Hoffert et al., 1979; Follows et al., 1996; Orr et al., 1999) or Bracket and Bisection (see Press et al. (1992), for a general description of these methods of solution). While this does not present a heavy burden for modern computers there is some motivation to find and use simpler, more efficient schemes. Firstly, increasing interest in the combination of data and models has led to the application of adjoint modeling techniques to ocean biogeochemistry models (e.g. Schlitzer, 2002; Hill et al., 2004), sometimes aided by automatic differentiation tools (Giering and Kaminski, 1998). The simplified algorithm presented here is easily differentiated and, under many practical circumstances, requires no iterative steps. Secondly, in highly idealized box models of the ocean carbon cycle a significant fraction of the code and computation time may be tied up in the iterative solver. An efficient and compact method of solution is aesthetically pleasing and provides faster solution, especially when using interpreted languages such as MATLAB. Finally, though eddy resolving numerical ocean biogeochemistry models are becoming computationally feasible they still place a heavy demand on the most powerful current computers and saving a small fraction of total CPU time may be worthwhile.

We present a simplified method to solve for the local equilibrium of the carbonate chemistry system in numerical ocean biogeochemistry models. We show that the method, similar to that described by Bacastow (1981), can be applied without the need for iterations under most circumstances and provides a very accurate solution. A very complete definition of alkalinity can be applied simply at very little extra computational cost. It provides a compact, efficient and easily differentiated algorithm for determining $\mathrm{pCO}_{2}$.

In Section 2 we introduce some essential concepts, then in Section 3 we outline the compact scheme of solution and provide a recipe for its application. We discuss the accuracy of air-sea $\mathrm{CO}_{2}$ fluxes relative to the full, iterative method in Section 4. A full listing of the equations governing the carbonate system is provided in Appendix A and an example FORTRAN code for the solver is provided in Appendix B.

\section{Modelling the ocean carbonate system}

First we review some pertinent aspects of ocean carbonate chemistry. Detailed reviews and discussions can be found in DOE, 1994; Millero, 1995; Morel and Hering, 1993; Stumm and Morgan, 1996; and Zeebe and Wolf-Gladrow, 2001. In the aqueous system dissolved carbon dioxide, $\mathrm{CO}_{2}(\mathrm{aq})$, forms carbonic acid, $\mathrm{H}_{2} \mathrm{CO}_{3}$, and dissociates into bicarbonate, $\mathrm{HCO}_{3}^{-}$, and carbonate, $\mathrm{CO}_{3}^{2-}$, forms:

$$
\begin{aligned}
& \mathrm{CO}_{2}(\mathrm{aq})+\mathrm{H}_{2} \mathrm{O} \rightleftharpoons \mathrm{H}_{2} \mathrm{CO}_{3} \\
& \mathrm{H}_{2} \mathrm{CO}_{3} \rightleftharpoons \mathrm{HCO}_{3}^{-}+\mathrm{H}^{+} \\
& \mathrm{HCO}_{3}^{-}+\mathrm{H}_{2} \mathrm{O} \rightleftharpoons \mathrm{CO}_{3}^{2-}+\mathrm{H}^{+}
\end{aligned}
$$

Since $\mathrm{CO}_{2}$ (aq) and $\mathrm{H}_{2} \mathrm{CO}_{3}$ are difficult to distinguish it is customary to refer to their combined aqueous concentration, which we represent here by $\left[\mathrm{CO}_{2}^{*}\right]$. In ocean carbon cycle models the prognostic variable is dissolved inorganic carbon, $C$, the sum of carbonate species in a water parcel since it is conservative with respect to advection and mixing:

$$
C=\left[\mathrm{CO}_{2}^{*}\right]+\left[\mathrm{HCO}_{3}^{-}\right]+\left[\mathrm{CO}_{3}^{2-}\right]
$$


In a numerical model, we are typically seeking to evaluate the air-sea flux of $\mathrm{CO}_{2}$, $K_{\mathrm{g}} K_{0}\left(p \mathrm{CO}_{2}^{\text {at }}-p \mathrm{CO}_{2}\right)$ where $K_{\mathrm{g}}$ is the air-sea gas transfer coefficient and $K_{0}$ is the solubility of $\mathrm{CO}_{2}$ such that

$$
p \mathrm{CO}_{2}=\frac{\left[\mathrm{CO}_{2}^{*}\right]}{K_{0}(T, S)}
$$

$K_{0}$ is an empirically determined function of temperature, salinity and pressure (Weiss, 1974). In order to evaluate the air-sea flux we must solve for the partitioning of $C$ between its components; specifically $\left[\mathrm{CO}_{2}^{*}\right]$.

Reactions (1)-(3) proceed to equilibrium on timescales of minutes so we assume equilibrium partitioning of the carbonate species within $C$. The relative abundances can be quantified using empirically determined (temperature, salinity and pressure dependant) equilibrium coefficients (e.g. Millero, 1995):

$$
\begin{aligned}
& K_{1}=\frac{\left[\mathrm{HCO}_{3}^{-}\right]\left[\mathrm{H}^{+}\right]}{\left[\mathrm{CO}_{2}^{*}\right]} \\
& K_{2}=\frac{\left[\mathrm{CO}_{3}^{2-}\right]\left[\mathrm{H}^{+}\right]}{\left[\mathrm{HCO}_{3}^{-}\right]}
\end{aligned}
$$

We now have four relations (4)-(7), and five unknowns ([ $\left.\left.\mathrm{HCO}_{3}^{-}\right],\left[\mathrm{CO}_{3}^{2-}\right],\left[\mathrm{CO}_{2}^{*}\right],\left[\mathrm{H}^{+}\right],\left[p \mathrm{CO}_{2}\right]\right)$. We can find the relationship between $p \mathrm{CO}_{2}$ and hydrogen ion concentration,

$$
p \mathrm{CO}_{2}=\frac{C}{K_{0}}\left[1+\frac{K_{1}}{\left[\mathrm{H}^{+}\right]}+\frac{K_{1} K_{2}}{\left[\mathrm{H}^{+}\right]^{2}}\right]^{-1}=\mathbf{H}\left(\left[\mathrm{H}^{+}\right]\right)
$$

but further constraints are required to solve for both $\left[\mathrm{H}^{+}\right]$and $p \mathrm{CO}_{2}$. An expression for alkalinity provides an additional constraint, bringing to bear the requirement for charge balance. Here we define the titration alkalinity, $A_{\mathrm{T}}$ (following Dickson, 1981; DOE, 1994):

$$
\begin{aligned}
A_{\mathrm{T}}= & {\left[\mathrm{HCO}_{3}^{-}\right]+2\left[\mathrm{CO}_{3}^{2-}\right]+\left[\mathrm{B}(\mathrm{OH})_{4}^{-}\right]+\left[\mathrm{OH}^{-}\right]+\left[\mathrm{HPO}_{4}^{2-}\right]+2\left[\mathrm{PO}_{4}^{3-}\right]+\left[\mathrm{SiO}(\mathrm{OH})_{3}^{-}\right] } \\
& -\left[\mathrm{H}^{+}\right]-\left[\mathrm{H}_{3} \mathrm{PO}_{4}\right]
\end{aligned}
$$

We have neglected contributions from ammonium, sulphur, fluorine and other minor species which are not resolved in the model we examine in later sections. However, additional contributions can easily be incorporated as necessary.

The alkalinity, $A_{\mathrm{T}}$ is determined by the concentration of the strong ions, such as $\left[\mathrm{Ca}^{2+}\right]$, in the water sample (see, for example, Zeebe and Wolf-Gladrow, 2001) which is not directly dependent upon $\mathrm{pH}$ but determined by freshwater fluxes, riverine inputs, fluxes to and from sediments and biological transformations. $A_{\mathrm{T}}$ in the modern open ocean generally ranges between 2250.0 and $2450.0 \mu \mathrm{eq} \mathrm{kg}^{-1}$. In numerical models surface ocean $A_{\mathrm{T}}$ is sometimes specified (as a constant value or empirically determined function of salinity) or can be a prognostic variable influenced by freshwater fluxes and biological cycling of calcium and nitrate. Since $A_{\mathrm{T}}$ is defined or carried in such models, (9) provides a constraint on the carbonate system along with several further unknowns. Additional, laboratory determined, equilibrium coefficients, $K_{\mathrm{Si}}, K_{\mathrm{P} 1}, K_{\mathrm{P} 2}, K_{\mathrm{P} 3}$ (DOE, 1994; Millero, 1995) define the relationship of these minor species to total dissolved inorganic boron, $B_{\mathrm{T}}$, dissolved inorganic phosphorus, $P_{\mathrm{T}}$, and dissolved inorganic silica, $S i_{\mathrm{T}}$. 
If $C, A_{\mathrm{T}}, P_{\mathrm{T}}, B_{\mathrm{T}}$, and $S i_{\mathrm{T}}$ are prognostic variables of the numerical model, or can be otherwise specified, the ten relationships defined in Appendix A can be solved for the remaining ten unknown variables. Here we wish to evaluate $\left[\mathrm{CO}_{2}^{*}\right]$ and hence the partial pressure of $\mathrm{CO}_{2}$.

\section{Solving for $\left[\mathrm{H}^{+}\right]$and $p \mathrm{CO}_{2}$}

Typically a set of equations similar to that in Appendix A is manipulated to eliminate all other variables and find a polynomial expression in $\left[\mathrm{H}^{+}\right]$. The coefficients are functions of $C, A_{\mathrm{T}}, B_{\mathrm{T}}$, $S i_{\mathrm{T}}, P_{\mathrm{T}}$ and the temperature and salinity dependent equilibrium coefficients. The appropriate root is found using an iterative method such as Newton-Raphson iteration (e.g. Hoffert et al., 1979). Once $\left[\mathrm{H}^{+}\right]$has been evaluated to sufficient accuracy, $p \mathrm{CO}_{2}$ may be determined using (18).

Here we present an alternative compact, simple and accurate algorithm for solving the surface ocean carbonate system which may generally be applied in three-dimensional ocean biogeochemistry models without the need for iteration. Truncating the expression for alkalinity, (9), to include only the leading order contributions on the right hand side defines the "carbonate alkalinity",

$$
A_{\mathrm{C}}=\left[\mathrm{HCO}_{3}^{-}\right]+2\left[\mathrm{CO}_{3}^{2-}\right]
$$

Combining this expression, the definition of dissolved inorganic carbon, (4), and the thermodynamic equilibrium expressions, (6) and (7), leads to a quadratic function of $\left[\mathrm{H}^{+}\right]$where the positive root is the appropriate solution,

$$
\left[\mathrm{H}^{+}\right]=\frac{1}{2}\left((\gamma-1) K_{1}+\left\{(1-\gamma)^{2} K_{1}^{2}-4 K_{1} K_{2}(1-2 \gamma)\right\}^{\frac{1}{2}}\right)=\mathbf{G}\left(A_{\mathrm{C}}, C\right)
$$

where $\gamma=\frac{C}{A_{\mathrm{C}}}$. Assuming $A_{\mathrm{C}} \sim A_{\mathrm{T}}$, and neglecting the contributions of minor species to alkalinity enables approximate analytic solutions which provide a great deal of insight into the carbonate system (e.g. Broecker and Peng, 1982) but such solutions are not sufficiently accurate for more quantitative applications. We can, however, make use of this direct solution for $\left[\mathrm{H}^{+}\right]$: Rearranging (9), $A_{\mathrm{C}}$ can be expressed in terms of $A_{\mathrm{T}}$,

$$
\begin{aligned}
& A_{\mathrm{C}}=A_{\mathrm{T}}+\mathbf{F}\left(\left[\mathrm{H}^{+}\right]\right) \\
& \mathbf{F}\left(\left[\mathrm{H}^{+}\right]\right)=-\left[\mathrm{B}(\mathrm{OH})_{4}^{-}\right]-\left[\mathrm{OH}^{-}\right]-\left[\mathrm{HPO}_{4}^{2-}\right]-2\left[\mathrm{PO}_{4}^{3-}\right]-\left[\mathrm{SiO}(\mathrm{OH})_{3}^{-}\right]+\left[\mathrm{H}^{+}\right]+\left[\mathrm{H}_{3} \mathrm{PO}_{4}\right]
\end{aligned}
$$

where $\mathbf{F}$ gathers the minor contributions to the titration alkalinity. $A_{\mathrm{T}}$ is a prognostic variable (or specified) in numerical models and so $\mathbf{F}$ and $A_{\mathrm{C}}$ can be evaluated using a first guess of $\left[\mathrm{H}^{+}\right]$. This estimate of $A_{\mathrm{C}}$ may be used to find an improved estimate of $\left[\mathrm{H}^{+}\right]$, from (11), which is then used to evaluate $\mathrm{pCO}_{2}$ with (8). Typically, in numerical models of ocean biogeochemistry, the local $\mathrm{pH}$ changes very little from one timestep to the next so using the value from the previous timestep as the initial guess provides a sufficiently accurate solution for $p \mathrm{CO}_{2}$ in this way.

The sequence of solution is described more succinctly as follows, where $\underline{x}$ is the location of a surface grid point in the model, $t$ denotes the current model time step, and $t-\delta t$ denotes the previous timestep: 
(1) Inputs: $C(\underline{x}, t), A_{\mathrm{T}}(\underline{x}, t), P_{\mathrm{T}}(\underline{x}, t), \mathrm{Si}_{\mathrm{T}}(\underline{x}, t), B_{\mathrm{T}}(\underline{x}, t)$, thermodynamic equilibrium coefficients $K_{i}(\underline{x}, t, T, S)$.

(2) Initial guess of hydrogen ion concentration $H^{0}$.

Cold start, $H^{0}=10^{-8} \mathrm{molkg}^{-1}$, otherwise, $H^{0}=\left[\mathrm{H}^{+}\right](\underline{x}, t-\delta t)$.

(3) $A_{\mathrm{C}}^{0}(\underline{x}, t)=A_{\mathrm{T}}(\underline{x}, t)+\mathbf{F}\left(\mathrm{H}^{0}\right)$.

(4) $\left[\mathrm{H}^{+}\right](\underline{x}, t)=\mathbf{G}\left(A_{\mathrm{C}}^{0}(\underline{x}, t), C(\underline{x}, t)\right)$.

(Return to 2 if necessary; $\left.H^{0}=\left[\mathrm{H}^{+}\right](\underline{x}, t)\right)$.

(5) $p \mathrm{CO}_{2}(\underline{x}, t)=\mathbf{H}\left(\left[\mathrm{H}^{+}\right](\underline{x}, t)\right)$.

The functions $\mathbf{F}, \mathbf{G}, \mathbf{H}$ are defined in (11), (12) and (8) respectively. An example FORTRAN listing of this algorithm (without iteration) is provided in the appendix.

Typically in a three-dimensional ocean biogeochemistry model tracer timesteps are on the order of hours or less, over which timescale changes in surface $\mathrm{pH}$ are likely to be very small. Hence, when solving for $p \mathrm{CO}_{2}(x, y)$ at each timestep, using the value of $\left[\mathrm{H}^{+}\right](x, y)$ from the previous timestep as the initial guess is sufficient for accurate solution without iteration. (This is discussed quantitatively in Section 4). In some circumstances, such as the "cold start" of a model from arbitrary initial conditions, and where the equilibrium $\left[\mathrm{H}^{+}\right]$has not yet been determined steps $2-5$ can be applied repeatedly, updating and refining the estimate of $\left[\mathrm{H}^{+}\right]$towards the correct value (as did Bacastow (1981)). The scheme is very stable and more robust to a wide range of arbitrary initial value of $\left[\mathrm{H}^{+}\right]$than is the Newton-Raphson method, where it is possible to move towards an inappropriate root of the equation.

\section{How accurate is the approximate solution?}

The degree of accuracy of this approximate method, with no iterations, relies upon the accuracy of the evaluation of the correction term, $\mathbf{F}$, which in turn depends upon the first guess of hydrogen ion concentration, $H^{0}$. How accurate must $H^{0}$ be in order to provide a sufficiently accurate estimate of $p \mathrm{CO}_{2}$ in a without iteration? A simple scaling argument provides some insight. Since the accuracy of the method hinges on the approximate estimation of carbonate alkalinity we first consider the sensitivity of $p \mathrm{CO}_{2}$ to $A_{\mathrm{C}}$. From the definition of carbonate alkalinity, (10), the carbonate thermodynamic equilibria, (6) and (7), and solubility of $\mathrm{CO}_{2},(5)$, we find an expression for $p \mathrm{CO}_{2}$ in terms of $A_{\mathrm{C}}$ and $\left[\mathrm{H}^{+}\right]$, analagous to (8):

$$
p \mathrm{CO}_{2}=\frac{A_{\mathrm{C}}}{K_{0}}\left[\frac{K_{1}}{\left[\mathrm{H}^{+}\right]}+\frac{2 K_{1} K_{2}}{\left[\mathrm{H}^{+}\right]^{2}}\right]^{-1}
$$

Subtracting $p \mathrm{CO}_{2} * 1 /(8)$ from $p \mathrm{CO}_{2} * 1 /(13)$ and assuming that $K_{1} K_{2} /\left[\mathrm{H}^{+}\right]^{2} \gg 1$ (i.e $\left[\mathrm{CO}_{3}^{2-}\right] \gg$ $\left[\mathrm{CO}_{2}^{*}\right]$, appropriate for typical oceanic conditions) we find

$$
p \mathrm{CO}_{2} \sim \frac{\left(A_{\mathrm{C}}-C\right)\left[\mathrm{H}^{+}\right]^{2}}{K_{0} K_{1} K_{2}}
$$

Differentiating with respect to $A_{\mathrm{C}}$ we determine the sensitivity

$$
\frac{\partial p \mathrm{CO}_{2}}{\partial A_{\mathrm{C}}} \sim \frac{\left[\mathrm{H}^{+}\right]^{2}}{K_{0} K_{1} K_{2}} \sim O(1) \operatorname{atm}\left(\mathrm{mol} \mathrm{kg}^{-1}\right)^{-1}
$$


Evaluating the expression using typical oceanic values we find that a $1 \mathrm{~mol} \mathrm{~kg}^{-1}$ error in the estimation of $A_{\mathrm{C}}$ leads to an error of about $1 \mathrm{ppmv}$ in the estimated surface ocean $p \mathrm{CO}_{2}$. The annual mean air-sea partial pressure difference is observed to be as much as 80 ppmv (Takahashi et al., 2002) and can be greater on smaller space and time scales. Over large areas, for example the Southern Ocean, it is relatively small; on the order of 10 ppmv. This suggests that an inaccuracy in the determination of surface ocean $p \mathrm{CO}_{2}$ of 1 ppmv could lead to an error in the mean air-sea flux of order $10 \%$. Thus to ensure an accuracy of in the estimated air-sea flux of $1 \%$ or better without iteration $A_{\mathrm{C}}$, must be evaluated to an accuracy of $\pm 0.1 \mu \mathrm{mol} \mathrm{kg}{ }^{-1}$ or better.

\subsection{To what accuracy do we need the initial guess, $H^{0}$ ?}

Applying the approximate scheme without iteration $A_{\mathrm{C}}=A_{\mathrm{T}}+\mathbf{F}\left(H^{0}\right)$ and for the same level of accuracy we must evaluate $\mathbf{F}\left(H^{0}\right)$ to within $\pm 0.1 \mu \mathrm{mol} \mathrm{kg}{ }^{-1}$. What does this imply for $H^{0}$ ? To leading order $\mathbf{F} \sim-\left[\mathrm{B}(\mathrm{OH})_{4}^{-}\right]$and so, using the thermodynamic equilibrium relationship for borate (Appendix A), the relationship between $\mathbf{F}$ and $H^{0}$ is

$$
\mathbf{F} \sim-\frac{K_{\mathrm{b}} B_{\mathrm{T}}}{K_{\mathrm{b}}+\mathrm{H}^{0}}
$$

Differentiating this expression with respect to $H^{0}$ and imposing reasonable oceanic parameter values we estimate the sensitivity to be

$$
\frac{\partial \mathbf{F}}{\partial \mathrm{H}^{0}} \sim-3 \times 10^{3}
$$

Now combining (17) and (15) we estimate that to evaluate $p \mathrm{CO}_{2}$ at an accuracy of $0.1 \mathrm{ppmv}$ (with respect to an iterative solution) $H^{0}$ must reflect the true value of $\left[\mathrm{H}^{+}\right]$to within $\pm 3 \times 10^{-11} \mathrm{~mol} \mathrm{~kg}^{-1}$. Since the variations in $\mathrm{pH}$ are typically very small in most ocean model applications this level of accuracy can be achieved simply by using the local $\left[\mathrm{H}^{+}\right](x, y)$ at the previous model timestep for $H^{0}(x, y)$. Uncertainties in the knowledge of the air-sea gas transfer coefficient are likely to be much more significant than this approximation.

In the case of a coarse resolution global model with a tracer timestep of $12 \mathrm{~h}$ and monthly variations in forcing. If $\mathrm{pH}$ varies smoothly over the seasonal cycle by about 0.1 units (around a mean value of about 8) then the change in $\left[\mathrm{H}^{+}\right](x, y)$ over one timestep will be approximately $3 \times 10^{-12} \mathrm{~mol} \mathrm{~kg}^{-1}$, an order of magnitude smaller than the criterion noted above. In Section 4.3 we demonstrate that, in such a model, using the local value of $\left[\mathrm{H}^{+}\right]$determined at the previous model timestep to provide $H^{0}$ leads to very accurate solutions without iteration.

At higher resolution, or when driven with synoptic physical forcing, then there may be more abrupt changes. If the same 0.1 change in $\mathrm{pH}$ occurs over three days in a model then, using a shorter tracer timestep of $2 \mathrm{~h}$, the error in $H^{0}$ will be on the same order as the criterion for estimating $p \mathrm{CO}_{2}$ to within $0.1 \mathrm{ppmv}$.

\subsection{How significant are truncations to the definition of total alkalinity?}

As a comparison, we consider the error introduced by estimating $A_{\mathrm{C}}$ without accounting for the the regional and seasonal variations in $\mathrm{P}$ and $\mathrm{Si}$ species which contribute to $A_{\mathrm{T}}$. In the Southern 
Ocean surface silicic acid concentrations can reach some tens of $\mu \mathrm{molkg} \mathrm{kg}^{-1}$ and ignoring the seasonal variation of $S i_{\mathrm{T}}$, for example, could lead to an error of as much as $\sim 30 \mu \mathrm{mol} \mathrm{kg}{ }^{-1}$ in the instantaneous, local value. Using the thermodynamic equilibrium relationship from Appendix A we see that this would lead to a corresponding error in $A_{\mathrm{C}}$ on the order of $1 \mu \mathrm{eq} \mathrm{kg}{ }^{-1}$. Applying (15) suggests that this, in turn, drives an error of about $1 \mathrm{ppmv}$ in $p \mathrm{CO}_{2}$ which is significant in this region of weak air-sea gradients and fluxes. In the following section we illustrate this impact in a global numerical model.

\subsection{Testing in a global biogeochemical model}

We test and illustrate the accuracy of the approximate method outlined above using an ocean biogeochemistry model (Fig. 1). It is based on the MIT ocean model (Marshall et al., 1997a,b) configured globally at coarse resolution $\left(2.8^{\circ} \times 2.8^{\circ}, 15\right.$ vertical levels $)$ and forced by monthly wind stresses, heat and fresh-water fluxes. The physical configuration is that described by Dutkiewicz et al. (2005) and the biogeochemical schemes used here are discussed in more detail by Parekh et al. (2005) and Ito et al. (2004). Tracers are transported by the residual mean flow where unresolved eddy transfers are parameterized according to Gent and McWilliams (1990). The tracer timestep is $12 \mathrm{~h}$. Prognostic biogeochemical model variables include dissolved inorganic carbon, $C$, alkalinity, phosphate, DOP and dissolved iron. Export production is modeled simply by a prescribed export rate modulated by light, phosphate or iron limitation as described by Parekh et al. (2005). The prognostic equation for $C$ (a discretized version of which forms the basis of any numerical carbon cycle model) is

$$
\frac{\partial C}{\partial t}=-U \cdot \nabla C+\nabla \cdot(K \nabla C)+S_{\mathrm{BIO}}-\frac{K_{\mathrm{g}} K_{0}}{\Delta z}\left(p \mathrm{CO}_{2}-p \mathrm{CO}_{2}^{\mathrm{at}}\right)
$$

where the first term on the right of (18) represents the advective transport of $C$, the second subgridscale mixing and eddy transfer processes, and the third represents biological consumption and regeneration of inorganic carbon. The last term on the right hand side represents the tendency in the surface layer of the model, thickness $\Delta z$, due to the air-sea flux of $\mathrm{CO}_{2}$. Here $K_{\mathrm{g}}$ is the gas transfer coefficient determined as a function of wind speed following Wanninkhof (1992) and $K_{0}$ is the solubility of $\mathrm{CO}_{2}$.

The model was initialized with appropriate global mean concentrations of dissolved inorganic carbon, $C$, alkalinity, $A_{\mathrm{T}}$ and phosphate, $\mathrm{PO}_{4}$ and integrated for about 10,000 years to an equilibrium state. In the spin-up period the carbonate system is solved using a traditional, NewtonRaphson iteration approach, with OCMIP protocols defining the expression for alkalinity (Orr et al., 1999). In the OCMIP protocol global mean surface values of $P_{\mathrm{T}}$ and $\mathrm{Si}_{\mathrm{T}}$ were used in the carbonate chemistry solver, here we use the local surface phosphate concentration and, since we are not resolving the silica cycle, the surface distribution of $\mathrm{Si}_{\mathrm{T}}$ is prescribed from a monthly climatology (Conkright et al., 2002). The modelled, pre-industrial ( $\left.p \mathrm{CO}_{2}^{\text {at }}=278.0 \mathrm{ppmv}\right)$, annual mean, sea-air flux exhibits plausible patterns (Fig. 1a). There is outgassing in the tropics, and some areas of the Southern Ocean, driven by the upwelling and warming of cool, deep waters rich in biogenic carbon. The subtropics and subpolar North Atlantic are taking $\mathrm{CO}_{2}$ from the atmosphere, driven by a combination of thermal solubility forcing and biological draw-down of surface C. While the details of the distribution are subject to the specific model used, assumptions about 

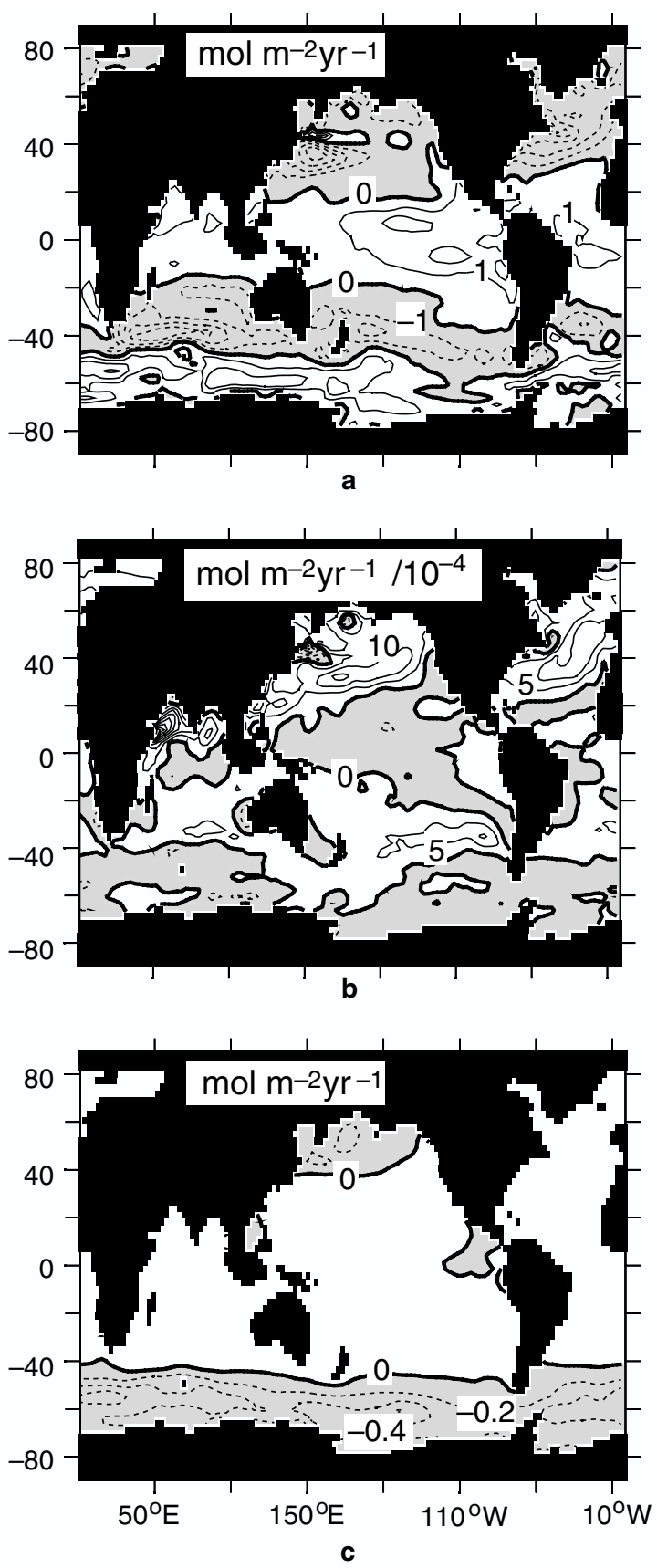

Fig. 1. (a) Modelled, steady-state, pre-industrial air-sea flux of $\mathrm{CO}_{2}\left(\mathrm{molm}^{-2}\right.$ year $\left.{ }^{-1}\right)$. (b) Difference in annual mean sea-air flux of $\mathrm{CO}_{2}$ determined using the iterative method (a) and the approximate method $\left(\mathrm{molm}^{-2}\right.$ year ${ }^{-1} / 10^{-4}$; iterative - approximate). Notice change in scale relative to (a). (c) Difference in annual sea-air flux of $\mathrm{CO}_{2}$ calculated with and without temporal and spatial variations of $P_{\mathrm{T}}$ and $S i_{\mathrm{T}}$ in the definition of alkalinity. (molm ${ }^{-2}$ year ${ }^{-1}$; varying-global mean).

the pre-industrial world and other factors, the broad patterns and magnitudes are generally plausible in the light of observations of todays, anthropogenically perturbed system (Takahashi et al., 
2002) and this model provides a reasonable testbed for considering the numerical schemes discussed here. (We note that if the historical increase in atmospheric $p \mathrm{CO}_{2}$ is imposed, the sea-to-air flux in the high latitude Southern Ocean changes sign by the late 20th century.)

To demonstrate the accuracy of the approximate $p \mathrm{CO}_{2}$ solver we perform a side by side comparison in which the air-sea flux is evaluated in a further year of integration of the model, picking up from the spun-up state. During this further year the air-sea flux is evaluated at each time-step using the traditional, iterative scheme and the approximate method (no iterations). The model is stepped forward each timestep using the flux estimated with the traditional scheme and we evaluate the annual mean flux estimated by each method. By comparing in this way we eliminate all other potential sources of difference such as model drift. Examination of the difference between the two evaluations of sea-air flux shows that the two methods are, for practical purposes, indistinguishable (Fig. 1b) in this case. The simple scheme reproduces the air-sea flux determined by the iterative method to within $0.1 \%$ over the whole domain and generally much better (notice that the scale in Fig. 1b is four orders of magnitude smaller than that of Fig. 1a). There is some regional structure; in particular the approximate method tends to underestimate (by a very small margin) the uptake rate of the northern basins. In this configuration using the Newton-Raphson iteration method to solve the surface carbonate system uses approximately $10 \%$ of the total CPU time. This is halved when using the non-iterative method presented here; a modest saving but one which might be significant for intensive, eddy-resolving calculations.

Since the surface concentrations of macro-nutrients (i.e. $\mathrm{Si}_{\mathrm{T}}$ and $P_{\mathrm{T}}$ ) vary strongly between subtropical and subpolar oceans, neglecting these contributions can be significant. Comparing evaluations of the annual sea-air flux using both fully variable distributions of $\mathrm{Si}_{\mathrm{T}}$ and $P_{\mathrm{T}}$ compared to using the global surface mean concentrations indicates an error in the air-sea flux of $\mathrm{CO}_{2}$ of up to $0.4 \mathrm{molm}^{-2}$ year $^{-1}$ in this configuration (Fig. 1c). (Here we made the comparison in the same way as that for the iterative and approximate numerical schemes.) The induced error is significant; as much as $50 \%$ of the mean flux in some areas of Southern Ocean where surface nutrient concentrations are elevated and mean fluxes relatively small. This result is consistent with expectations from the scaling argument in Section 4 . We note that the neglect of fully variable $\mathrm{Si}_{\mathrm{T}}$ and $P_{\mathrm{T}}$ in the expression for alkalinity will not be a significant problem for many numerical sensitivity studies, where model results are compared to a reference case performed in the same way. However, it could be an important issue for state estimation efforts, where model and observations are intimately combined. The errors incurred by neglecting the minor contributions to alkalinity are significantly greater than that incurred using the approximate carbonate system solver. Indeed, one of the advantages of this method of solution is that it is very simple to increase the accuracy of the definition of alkalinity by adding an additional term to $\mathbf{F}$.

\section{Summary and discussion}

We have presented an accurate and simple method for finding the equilibrium partitioning of the carbonate system in the upper ocean and thus evaluating the air-sea flux of $\mathrm{CO}_{2}$ in numerical models. The method has several advantages over the iterative schemes typically used: it is more robust, the code is cleaner and more compact and the scheme is computationally more efficient. The algorithm and code are ideal for the adjoint model approach to data assimilation and state 
estimation since it is easily differentiated, requires no iterative procedure but retains a complete definition of alkalinity. The accuracy of the scheme is more than sufficient for the purposes of ocean carbon cycle model studies given, for example, the uncertainty in the gas transfer coefficient.

\section{Acknowledgements}

We thank Payal Parekh and Andrew Dickson for helpful discussions and two anonymous reviewers for insightful comments and suggestions. We are grateful for support from PARADIGM NOPP and NOAA.

\section{Appendix A}

Given values for $C, A_{\mathrm{T}}, P_{\mathrm{T}}, B_{\mathrm{T}}, \mathrm{Si}_{\mathrm{T}}$, and the equilibrium coefficients $K_{i}(T, S)$, the following ten equations can be solved to determine $p \mathrm{CO}_{2}=\left[\mathrm{CO}_{2}^{*}\right] / K_{0}$.

$$
\begin{aligned}
& C=\left[\mathrm{CO}_{2}^{*}\right]+\left[\mathrm{HCO}_{3}^{-}\right]+\left[\mathrm{CO}_{3}^{2-}\right] \\
& A_{\mathrm{T}}=\left[\mathrm{HCO}_{3}^{-}\right]+2\left[\mathrm{CO}_{3}^{2-}\right]+\left[\mathrm{B}(\mathrm{OH})_{4}^{-}\right]+\left[\mathrm{OH}^{-}\right]+\left[\mathrm{HPO}_{4}^{2-}\right] \\
& +2\left[\mathrm{PO}_{4}^{3-}\right]+\left[\mathrm{SiO}(\mathrm{OH})_{3}^{-}\right]-\left[\mathrm{H}^{+}\right]-\left[\mathrm{H}_{3} \mathrm{PO}_{4}\right] \\
& K_{1}=\frac{\left[\mathrm{HCO}_{3}^{-}\right]\left[\mathrm{H}^{+}\right]}{\left[\mathrm{CO}_{2}^{*}\right]} \\
& K_{2}=\frac{\left[\mathrm{CO}_{3}^{2-}\right]\left[\mathrm{H}^{+}\right]}{\left[\mathrm{HCO}_{3}^{-}\right]} \\
& K_{\mathrm{w}}=\left[\mathrm{H}^{+}\right]\left[\mathrm{OH}^{-}\right] \\
& {\left[\mathrm{B}(\mathrm{OH})_{4}^{-}\right]=\frac{K_{\mathrm{b}} B_{\mathrm{T}}}{K_{\mathrm{b}}+\left[\mathrm{H}^{+}\right]}} \\
& {\left[\mathrm{SiO}(\mathrm{OH})_{3}^{-}\right]=\frac{K_{\mathrm{Si}} \mathrm{Si}_{\mathrm{T}}}{K_{\mathrm{Si}}+\left[\mathrm{H}^{+}\right]}} \\
& {\left[\mathrm{H}_{3} \mathrm{PO}_{4}\right]=\frac{P_{\mathrm{T}}\left[\mathrm{H}^{+}\right]^{3}}{\left[\mathrm{H}^{+}\right]^{3}+K_{\mathrm{P} 1}\left[\mathrm{H}^{+}\right]^{2}+K_{\mathrm{P} 1} K_{\mathrm{P} 2}\left[\mathrm{H}^{+}\right]+K_{\mathrm{P} 1} K_{\mathrm{P} 2} K_{\mathrm{P} 3}}} \\
& {\left[\mathrm{HPO}_{4}^{2-}\right]=\frac{P_{\mathrm{T}} K_{\mathrm{P} 1} K_{\mathrm{P} 2}\left[\mathrm{H}^{+}\right]}{\left[\mathrm{H}^{+}\right]^{3}+K_{\mathrm{P} 1}\left[\mathrm{H}^{+}\right]^{2}+K_{\mathrm{P} 1} K_{\mathrm{P} 2}\left[\mathrm{H}^{+}\right]+K_{\mathrm{P} 1} K_{\mathrm{P} 2} K_{\mathrm{P} 3}}} \\
& {\left[\mathrm{PO}_{4}^{3-}\right]=\frac{P_{\mathrm{T}} K_{\mathrm{P} 1} K_{\mathrm{P} 2} K_{\mathrm{P} 3}}{\left[\mathrm{H}^{+}\right]^{3}+K_{\mathrm{P} 1}\left[\mathrm{H}^{+}\right]^{2}+K_{\mathrm{P} 1} K_{\mathrm{P} 2}\left[\mathrm{H}^{+}\right]+K_{\mathrm{P} 1} K_{\mathrm{P} 2} K_{\mathrm{P} 3}}}
\end{aligned}
$$

$B_{\mathrm{T}}, S i_{\mathrm{T}}$ and $P_{\mathrm{T}}$ are total dissolved inorganic boron, silica and phosphorus concentrations respectively. Equilibrium coefficients $K_{\mathrm{Si}}, K_{\mathrm{b}}, K_{\mathrm{w}}, K_{\mathrm{P} 1}, K_{\mathrm{P} 2}$ and $K_{\mathrm{P} 3}$ are laboratory determined functions of temperature, salinity and pressure (see DOE, 1994; Millero, 1995; Zeebe and Wolf-Gladrow, 2001). 


\section{Appendix B}

c.................................................

c Example FORTRAN subroutine: solve carbonate system for pC02

c M. Follows, T. Ito, S. Dutkiewicz

c.

subroutine calc_pCO $\mathrm{CO}_{2}(\mathrm{dic}, \mathrm{pt}$,sit,bt,ta,ff,k1,k2, \& k1p,k2p,k3p,kb,kw,ksi,H,pCO2)

c routine variables

real pt,sit,ta,pCO2,dic,H,ff,bt,k1,k2,k1p,k2p,k3p,kb,kw,ksi

c local variables

real gamm,co2s,hg,cag,bohg,h3po4g,h2po4g,hpo4g,po4g, \& siooh3g,denom,dummy,fg

$c$ dic $=$ dissolved inorganic carbon; $p t=$ dissolved inorganic phosphorus

$c$ sit $=$ dissolved inorganic silica, $b t=$ dissolved inorganic boron

c ta = total alkalinity; $c a=$ carbonate alkalinity; $\mathrm{H}=[\mathrm{H}+]$

c pCO2 = partial pressure $\mathrm{CO} ;$;f = fugacity of $\mathrm{CO} 2$

$c k 1, k 2=$ carbonate equilibrium coeffs; $k w=$ dissociation of water

c klp, $k 2 p, k 3 p=$ phosphate equilibrium coefficients

$c k s i, k b=$ silicate and borate equilibrium coefficients

c Equilibrium relationships from DOE handbook (DOE, 1994):

$c$ coefficients evaluated elsewhere and passed in.

$c$ First guess of $[\mathrm{H+}]$ : from last timestep $* O R^{*}$ fixed for cold start

$\mathrm{hg}=\mathrm{H}$

c estimate contributions to total alk from borate, silicate, phosphate

bohg $=\mathrm{bt} * \mathrm{~kb} /(\mathrm{hg}+\mathrm{kb})$

siooh3g $=$ sit*ksi/(ksi $+\mathrm{hg})$

denom $=$ hg*hg*hg $+(k 1 p * h g * h g)+(k 1 p * k 2 p * h g)+(k 1 p * k 2 p * k 3 p)$

$\mathrm{h} 3 \mathrm{po} 4 \mathrm{~g}=(\mathrm{pt} * \mathrm{hg} * \mathrm{hg} * \mathrm{hg}) /$ denom

$\mathrm{h} 2 \mathrm{po} 4 \mathrm{~g}=(\mathrm{pt} * \mathrm{k} 1 \mathrm{p} * \mathrm{hg} * \mathrm{hg}) /$ denom

hpo $4 \mathrm{~g}=(\mathrm{pt} * \mathrm{k} 1 \mathrm{p} * \mathrm{k} 2 \mathrm{p} * \mathrm{hg}) /$ denom

$\mathrm{po} 4 \mathrm{~g}=(\mathrm{pt} * \mathrm{k} 1 \mathrm{p} * \mathrm{k} 2 \mathrm{p} * \mathrm{k} 3 \mathrm{p}) /$ denom

c estimate carbonate alkalinity

$\mathrm{fg}=-$ bohg $-(\mathrm{kw} / \mathrm{hg})+\mathrm{hg}-\mathrm{hpo} 4 \mathrm{~g}-2.0 *$ po $4 \mathrm{~g}+\mathrm{h} 3 \mathrm{po} 4 \mathrm{~g}-\operatorname{siooh} 3 \mathrm{~g}$

$\mathrm{cag}=\mathrm{ta}+\mathrm{fg}$

$c$ improved estimate of hydrogen ion conc

gamm $=$ dic/cag

dummy $=(1.0$-gamm $) *(1.0$-gamm $) * \mathrm{k} 1 * \mathrm{k} 1-4.0 * \mathrm{k} 1 * \mathrm{k} 2 *(1.0-2.0 *$ gamm $)$

$\mathrm{H}=0.5 *(($ gamm-1.0$) * \mathrm{k} 1+\operatorname{sqrt}($ dummy $))$

c evaluate [CO2* $]$

$\mathrm{co} 2 \mathrm{~s}=\mathrm{dic} /(1.0+(\mathrm{k} 1 / \mathrm{H})+(\mathrm{k} 1 * \mathrm{k} 2 /(\mathrm{H} * \mathrm{H})))$

$c$ evaluate surface $p \mathrm{CO} 2$

$\mathrm{pCO} 2=\operatorname{co} 2 \mathrm{~s} / \mathrm{ff}$

return

end

c. 


\section{References}

Bacastow, R., 1981. Numerical evaluation of the evasion factor. In: Bolin, B. (Ed.), Carbon Cycle Modelling, SCOPE 16. J. Wiley and Sons, N.Y., pp. 95-101.

Broecker, W.S., Peng, T.H., 1982. Tracers in the Sea. Eldigio Press, Palisades, NY.

Conkright, M.E., Garcia, H.E., O’Brien, T.D., Locarnini, R.A., Boyer, T.P., Stephens, C., Antonov, J.I., 2002. World Ocean Atlas 2001, Volume 4: Nutrients, NOAA Atlas NESDIS, 52, U.S. Government Printing Office, Washington, D.C.

Dickson, A.G., 1981. An exact definition of total alkalinity, and a procedure for the estimation of alkalinity and total inorganic carbon from titration data. Deep-Sea Res. 28, 609-623.

DOE, 1994. Handbook of methods for the analysis of the various parameters of the carbon dioxide system in sea water (Version 2). Dickson, A.G., Goyet, C. (Eds.), ORNL/CDIAC-74.

Dutkiewicz, S.W., Follows, M.J., Parekh, P., 2005. Interactions of the iron and phosphorus cycles: a modelling study. Global Biogeochem. Cycles 19, GB1021. doi:10.1029/2004GB002342.

Follows, M.J., Williams, R.G., Marshall, J.C., 1996. Subduction of carbon in the North Atlantic subtropical gyre. J. Marine Res. 54, 605-630.

Gent, P., McWilliams, J., 1990. Isopycnal mixing in ocean circulation models. J. Phys. Oceanogr. 20, $150-155$.

Giering, R., Kaminski, T., 1998. Recipes for adjoint code construction. ACM Trans. Math, Software 24 (4), $437-474$.

Hill, C.N., Bugion, V., Follows, M.J., Marshall, J.C., 2004. Evaluating carbon sequestration efficiency in an ocean model using adjoint sensitivity analysis. J. Geophys. Res. 109, C11005. doi:10.1029/2002JC001598.

Hoffert, M.I., Wey, Y.-C., Callegari, A.J., Broecker, W.S., 1979. Atmospheric response to deep sea injections of fossil fuel carbon dioxide. Climate Change 2, 53-68.

Ito, T., Follows, M.J., Boyle, E.A., 2004. Is AOU a good measure of respiration in the oceans?. Geophys. Res. Lett. 31 L17305. doi:10.1029/2004GL020900.

Marshall, J.C., Hill, C., Perelman, L., Adcroft, A., 1997a. Hydrostatic, quasi-hydrostatic and non-hydrostatic ocean modeling. J. Geophys. Res. 102 (5), 733-5,752.

Marshall, J.C., Adcroft, A., Hill, C., Perelman, L., Heisey, C., 1997b. A finite-volume, incompressible Navier-Stokes model for the studies of the ocean on parallel computers. J. Geophys. Res 102 (5), 753-5,766.

Millero, F., 1995. Thermodynamics of the carbon dioxide system in the oceans. Geochimica et Cosmochimica Acta 59, 661-677.

Morel, F.M.M., Hering, J.G., 1993. Principles and Applications of Aquatic Chemistry. John Wiley and sons, inc.

Orr, J.C., Najjar, R., Sabine, C.L., Joos, F., 1999. Abiotic-HOWTO. Internal OCMIP Report, LSCE/CEA Saclay, Gifsur-Yvette, France, 25 pp., 1999.

Parekh, P., Follows, M.J., Boyle, E.A., in press. Decoupling of iron and phosphate in the global ocean. Global Biogeochem. Cycles.

Press, W.H., Teukolsky, S.A., Vetterling, W.T., Flannery, B.P., 1992. Numerical Recipes in Fortran, second ed. Cambridge University Press.

Schlitzer, R., 2002. Carbon export fluxes in the Southern Ocean: results from inverse modeling and comparison with satellite based estimates. Deep-Sea Res. II 49, 1623-1644.

Stumm, W., Morgan, J.J., 1996. Aquatic Chemistry, third ed. John Wiley and Sons, New York.

Takahashi, T., Sutherland, S.C., Sweeney, C., Poisson, A., Metzl, N., Tilbrook, B., Bates, N., Wanninkhof, R., Feely, R.A., Sabine, C., Olafssong, J., Nojiri, Y., 2002. Global sea-air $\mathrm{CO}_{2}$ flux based on climatological surface ocean $p \mathrm{CO}_{2}$, and seasonal biological and temperature effects. Deep-Sea Res. 49, 1601-1622.

Wanninkhof, R., 1992. Relationship between wind speed and gas exchange over the ocean. J. Geophys. Res. 97, 73737382.

Weiss, R.F., 1974. Carbon dioxide in water and seawater: the solubility of a non-ideal gas. Marine Chem. 2, $203-215$.

Zeebe, R.E., Wolf-Gladrow, D.A., 2001. $\mathrm{CO}_{2}$ in seawater: equilibrium, kinetics, isotopesElsevier Oceanography Series, Vol. 65. Elsevier, Amsterdam, pp. 346. 